escaped. A stout director was then introduced, and catching in a depression, a little pressure caused the bone to yield, and it was pushed on into the interior of the bone, and the opening enlarged by levering the director about in different directions. Pus now readily escaped, in quantity equal perhaps to half a teaspoonful or more. A poultice was directed to be applied, and care was also ordered to be taken to prevent the too rapid closure of the wound. I did not visit the patient after performing the operation, but heard of his immediate freedom from pain, his speedy convalescence, and of his soon being able to resume his occupation. In the early part of April, 1880, however, an opportunity was afforded me of again seeing him. He was then in perfect health-the perforation in the tympanic membrane was closed, and the hearing on this, the defective side, was much improved, the watch being audible at seventeen inches $=\left(\frac{17}{16}\right.$.)

Mastoid suppuration, or the minor affection, periostitis, is more frequently met with in connexion with chronic tympanic disease. In the present instance it assumed a more subacute form, and the patient was probably correct in assigning its cause to a metastasis of his gouty affection. The relation of gout to ear affections is referred to by Hinton, Kramer, and particularly by Harvey. Mastoid disease once set up becomes of serious importance, because, if neglected, septicæmia or pyæmia may prove the result. "An extension of the disease to the prain taking place either through the numerous foramina which transmit branches of the middle meningeal artery, or pus may be carried into the circulation through the mastoid vein which passes to the lateral sinus." Many of us must, however, have seen instances in which nature has herself relieved the disease, the evidence being in the sinuses and scars over the mastoid, especially in children. But the present case is, I believe, of interest and importance as exemplifying the good effects resulting from opening the mastoid when suppuration is diagnosed. It is merely the application of general surgical principles so frequently carried out in other regions.

The operation of trephining the mastoid was introduced two centuries ago. Doubtless it, and other procedures with the same object, are performed now more frequently than the scant reference to the subject in the general surgical works would lead one to suppose. In aural treatises its advantages are recognised, and finds amongst its supporters Hinton, Roosa, Troltsch, \&c. Roosa puts it that this sound surgical procedure may be fairly said to be established in practice. Twenty-six out of thirty-four cases he refers to, as recorded by Buck, resulted in recovery.

Speaking also of this operation, Von Troltsch says : "It is now to be included among those operative measures which may be demanded by the 'vital indication,' and just as every conscientious surgeon under definite circumstances will feel himself compelled to open the larynx or to operate for hernia, just so urgent conditions occur when perforation of the mastoid process remains as the only possible means of saving life." Sheffield.

\section{SACCHARINE URINE IN CHRONIC ECZEMA.}

By ROBERT LIVEING, M.D., F.R.C.P., PHYSICIAN TO THE DEPARTMENT FOR SKIN DISEASES AT MIDDLESEX HOSPITAL.

DLRLNG several years past $I$ have, as a matter of routine practice, tested the urine of all cases of obstinate eczema that have come under my care for sugar and albumen, and I find the presence of one or both very common. It is, however, the frequent presence of the former in the urine of those suffering from severe, obstinate eczema, to which I desire to call attention, and especially with reference to treatment.

One may say broadly that there are two principal and quite distinct groups of cases in which saccharine uriue occurs-(1) we have diabetes in its graver forms, depending on profound nervous lesion; and (2) grlycosuria, depending on defective assimilative processes, in which certain functions of the liver are especially at fault. It is only to the latter group that I wish to refer. The glycosuria which is met with in the latter half of life is neither uncommon nor always serious ; it is, as I have said, apt to be associated with very irritable and obstinate eczema, and in women the saccharine urive acts in addition as a local irritant, and makes the eczema about the pudendum almost intolerable; indeed, excessive and intractable irritation in this region in middleaged women is very commonly associated with sugar in the urine, and is often incurable as long as much sugar remains.

Now I come to the point to which I wish especially to draw attention, and that is that the eczema and the sugar in the above-named class of cases are mainly due to over-feeding. I use the term in its broadest sense, and include quality as well as quantity of food. I frequently meet with cases of intractable eczema pudendi in women past middle life, of sedentary habits, and eating three large meat meals a day, and trying by all means in their power to stimulate their appetite, under the erroneous impression that they are "keeping up their strength." Now, in these and similar cases, medicine and local treatment are almost equally useless, unless there is, at the same time, a thorough reform in the diet. The first point is to deprive the patients of sugar as an article of food, except just enough to make light puddings palatable. The reason for this is that much of the sugar passes the liver unchanged, and is therefore worse than useless as a food. The next point is greatly to reduce the animal food, especially mutton and beef, and to substitute for it simple clear soup, and poultry or fish in moderate quantity once a day. Lastly, the chief part of the daily diet should be made up of light farinaceous and milk food, such as bread, rice, and macaroni. This is, I know, contrary to the view often entertained, that saccharine urine should be treated by an animal diet, and that starch should be as much as possible excluded. Now, whatever good may result from such a diet in some cases, I am quite sure that it does not answer in those to which I refer; on the contrary, exactly the reverse holds, and the old routine practice, except so far as sugar is excluded, is quite wrong. I have seen the sugar disappear from the urine and the eczema depart under a change of diet such as I have above recommended. The truth is that many people at sixty, when the tissue changes are slow, eat as much or more than they did at twenty, when all the processes of change are at the height of their activity; what wonder then that unnatural work is thrown upon the skin, kidneys, and other excreting organs of the body. There is some substantial truth in the saying that small eaters live the longest.

Manchester-square, $W$.

\section{ON CONGESTIVE DYSMENORRHCEA.}

\section{BY G. ERNEST HERMAN, M.B. LOND.,}

assistaNT OBSTETRIC PHYSICIAN TO THE LONDON hosPITAL, PHYSICIAN

TO THE ROYAL MATERNITY CHARITY, HONORARY LIBRARIAN TO THE OBSTETRYCAL SOCIETY OF LONDON.

$$
\text { (Conctuded from p. 3.9.) }
$$

IT seems to me that if we have a menstrual pain which is caused by congestion of otherwise healthy pelvic organs, such congestion being brought about by some trifling and passing cause, this pain may with fair accuracy be called congestive dysmenorrhoea; and we may prefix to it the adjective "primary," to distinguish these cases from those in which the congestion is but secondary to some other morbid condition. I shall not discuss which are the parts most congested, or whether they ought to be called congestive or inflammatory. Of course congestion never arises without a cause; but the cause may be transitory, and the resulting changes of longer duration, so that we may be able to discover the latter only, or the cause may be so insignificant that our modes of investigation cannot detect it.

Supposing that cases of this kind of dysmenorrhca do exist, can any kind of proof be adduced that congestion is the sole cause of the pain? The only proof that I can imagine is, (1) that no other cause for the pain should be discoverable; and (2) that if the pain be due to hyperæmia, it should be relieved by depletion of the overfilled bloodvessels, and, if no abiding cause for the congestion be present, sufficient local bloodletting should cure the patient. Such cases are met with, and I will instance one.

A. $\mathrm{K} \longrightarrow$, aged forty-four, a canvasser's wife, came to the obstetric out-patient department of the London Hospital on Nov. 13th, 1878. Her complaints were of infrequent, scanty, and painful menstruation, of pain between the veriods in the right inguinal region, and of dysparcunia. S'se stated 